\section{OPEN ACCESS}

Edited by:

Catherine Cahill,

University of California, Irvine, USA

Reviewed by:

Philippe Seguela,

McGill University, Canada

Li Zhang,

National Institute on Alcohol Abuse and Alcoholism - National Institutes of Health, USA

${ }^{*}$ Correspondence:

Gongliang Zhang

gongliangzhang@hotmail.com;

Yong-Mei Zhang

zhangym700@163.com

tThese authors have contributed equally to this work

Specialty section: This article was submitted to Neuropharmacology, a section of the journal Frontiers in Pharmacology

Received: 08 January 2016 Accepted: 11 May 2016 Published: 30 May 2016

Citation:

Wang H, Tao X, Huang S-T, Wu L, Tang $H-L$, Song $Y$, Zhang $G$ and Zhang Y-M (2016) Chronic Stress Is Associated with Pain Precipitation and Elevation in DeltaFosb

Expression. Front. Pharmacol. 7:138. doi: 10.3389/fphar.2016.00138

\title{
Chronic Stress Is Associated with Pain Precipitation and Elevation in DeltaFosb Expression
}

Hang Wang ${ }^{1+}$, Xinrong Tao ${ }^{2 t}$, Si-Ting Huang ${ }^{1}$, Liang Wu' ${ }^{1}$, Hui-Li Tang ${ }^{1}$, Ying Song ${ }^{1}$,
Gongliang Zhang ${ }^{3 *}$ and Yong-Mei Zhang ${ }^{1 *}$

1 Jiangsu Province Key Laboratory of Anesthesiology, College of Anesthesiology, Xuzhou Medical University, Xuzhou, China, ${ }^{2}$ College of Medicine, Anhui University of Science and Technology, Huainan, China, ${ }^{3}$ School of Basic Medical Sciences,

Anhui Medical University, Hefei, China

A number of acute or repeated stimuli can induce expression of DeltaFosB ( $\Delta$ FosB), a transcription factor derived from the fosB gene (an osteosarcoma viral oncogene) via alternative splicing. $\triangle$ FosB protein is currently viewed as a 'molecular switch' to repeated stimuli that gradually converts acute responses into relatively stable adaptations underlying long-term neural and behavioral plasticity. $\Delta$ FosB has received extensive attention in drug addition, depression, and stress adaptation, but changes in $\Delta$ FosB protein expression during pain is not fully understood. In this study we explored $\triangle$ FosB expression in the medial prefrontal cortex (mPFC) of rats experiencing chronic or acute stress-induced pain. Our data reveal that chronic pain induced by neonatal colorectal distension, chronic constriction injury (CCl) of the sciatic nerve, or maternal separation was associated with an increase in $\triangle \mathrm{fosB}$ protein expression in $\mathrm{mPFC}$, but acute application of acetic acid or zymosan did not alter the $\Delta$ FosB protein expression. $\Delta$ FosB expression in the rat visual cortex, a non pain-related brain region, did not change in response to (CCl) of the sciatic nerve and acetic acid treatment. In conclusion, our results indicate that $\triangle$ FosB protein expression is significantly elevated in rats that have experienced chronic pain and stress, but not acute pain. The $\Delta$ FosB protein may serve as an important transcription factor for chronic stress-induced pain. Further research is needed to improve the understanding of both the upstream signaling leading to $\Delta$ FosB protein expression as well as the regulation of $\Delta$ FosB gene expression in cortical neurons.

Keywords: Deltafosb, $\Delta$ FosB, medial prefrontal cortex, pain, western blot

\section{INTRODUCTION}

Pain is associated with an alteration in gene expression and neuronal plasticity (Baliki et al., 2014) that can result in persistent structural and functional modifications (Woolf and Costigan, 1999; Ji et al., 2014). Transcription factors bridge the pathological events in the central nervous system (CNS) with alterations in gene expression during the pathogenesis of pain (Woolf and Costigan, 1999; Zhang et al., 2015). Transcription factors belonging to the Fos family may be important candidates for pain modulation (Luis-Delgado et al., 2006). Encoded by $c$ fos, fos B, fra-1, and fra-2 genes (Herdegen and Leah, 1998), Fos family proteins are induced rapidly and transiently in specific brain regions to regulate downstream gene expression 
in response to environmental factors (Sheng and Greenberg, 1990; Perrotti et al., 2004). These Fos family proteins form heterodimers with Jun family proteins (c-Jun, JunB, or JunD) to form functioning activator protein-1 (AP1) transcription factors that bind to AP1 consensus sites present in the promoters of certain genes to regulate their transcription. The DeltaFosB $(\triangle \mathrm{FosB})$ protein is a truncated splice variant of fos $B$, missing 101 amino acids at the C-terminal of the FosB protein (Nakabeppu and Nathans, 1991). Recently the $\Delta$ FosB protein has received extensive attention in drug addition, depression and stress adaptation (McClung and Nestler, 2003; Perrotti et al., 2004).

The $\Delta$ FosB protein is encoded by the fosB gene and shares homology with other Fos family proteins (Morgan and Curran, 1995). $\triangle$ FosB has the same dimerization and DNA-binding activities of FosB. Upon stress stimulus, the post-translational modifications of $\Delta \mathrm{FosB}$ protein lead to different protein isoforms with half-lives between $10 \mathrm{~h}$ and 8 days (McClung et al., 2004). Therefore, $\Delta$ FosB protein is assumed to function as a "molecular switch" that mediates persistent adaptations in the brain's response to repetitive or long-lasting stimuli (Nestler et al., 1999, 2001). In the CNS, $\triangle$ FosB has been examined in the context of electroconvulsive treatment and epilepsy (Morris et al., 2000), addiction (McClung and Nestler, 2003; Zhang et al., 2014), compulsive running (Werme et al., 2002), dyskinesia (Andersson et al., 2003), and stress (Perrotti et al., 2004). For instance, Zhang reported that $\Delta$ FosB overexpression decreases cocaine self-administration, enhances extinction of cocaine seeking, and decreases cocaine-induced reinstatement of intravenous cocaine self-administration (Zhang et al., 2014). However, limited evidence suggests an involvement of $\Delta$ FosB protein in acute or chronic stress-induced pain precipitation. Mice overexpressing the $\Delta$ FosB protein in the nucleus accumbens and the dorsal striatum displayed reduced analgesic responses to acute morphine administration as well as faster development of morphine tolerance (Zachariou et al., 2006). Carrageenan-induced inflammation increases $\Delta$ FosB protein expression in the spinal cord (Luis-Delgado et al., 2006). These reports suggest that $\Delta$ FosB may be an important molecular modulator participating in the pathogenesis of pain. To date, the direct evidence of changes in $\triangle F$ Fos $B$ protein expression in various pain models has not been reported.

Pain is associated with depression and cognitive decline (Metz et al., 2009; Zhang et al., 2015), suggesting an involvement of cortical areas associated with cognitive functions. The medial prefrontal cortex (mPFC) plays a critical role in pain-related depression and anxiety, which are frequent co-morbidities of chronic pain (Guida et al., 2015). Unilateral chronic constriction injury (CCI) to the infraorbital nerve induces a strong, bilateral upregulation of extracellular signal regulated kinases $1 / 2$ (pERK$1 / 2$ ) in the ventral mPFC in rats (Devoize et al., 2011). Stress induces $\triangle \mathrm{FosB}$ protein expression in $\mathrm{mPFC}$, and that overexpression of $\triangle$ FosB in pre-limbic mPFC enhances stress susceptibility in mice (Vialou et al., 2014). mPFC may be a key brain region through which the $\Delta \mathrm{FosB}$ protein modulates the establishment and maintenance of pain.
In the present study, we examined $\Delta$ FosB protein expression in $\mathrm{mPFC}$ in rodents that experienced acute and chronic stressinduced pain. The visual cortex, a non pain-related brain region, was used as a control. Our data reveal that chronic stress-induced pain was associated with an increase in the expression of $\mathrm{mPFC}$ $\Delta$ FosB protein, but $\Delta$ FosB expression did not change in rats that experienced acute stress-induced pain. These results illuminate a new molecular mechanism of pain, and may pave a new avenue for development of therapeutics against pain.

\section{MATERIALS AND METHODS}

\section{Animals}

Male Sprague-Dawley rats weighing 220 to $250 \mathrm{~g}$ and C57B mice weighing 21 to $24 \mathrm{~g}$ were obtained from the Experimental Animal Center of Xuzhou Medical University (Xuzhou, China) and housed in groups of four per standard polycarbonate cage and kept on a standard $12 \mathrm{~h}$ light/dark cycle (lights on at 07:00 a.m.), constant temperature and humidity $\left(22^{\circ} \mathrm{C}\right.$ and $50 \%$, respectively) with food provided ad libitum. All procedures were conducted in accordance with the guidelines described in the National Institutes of Health's Guide for the Care and Use of Laboratory Animals (NIH Publication No. 8023, revised 1978) and the International Association for the Study of Pain, and approved by the Institutional Animal Care and Use Committee at Xuzhou Medical College.

\section{Development of Pain Models Development of Visceral Hypersensitivity Rat Model with Colorectal Distensions}

Visceral hypersensitivity was induced by adult colorectal distension $(C R D)$ in rats that experience neonatal CRDs as described previously (Chen et al., 2015; Zhang et al., 2015). In brief, neonatal CRDs were induced on postnatal days 8,10 , and 12 using an angioplasty balloon (length, $20.0 \mathrm{~mm}$; diameter, $3.0 \mathrm{~mm}$ ) inserted into the upper rectum and descending colon (the section of the large intestine that travels back down toward the rectum). The balloon was distended with $0.3 \mathrm{ml}$ water at a pressure of $60 \mathrm{~mm} \mathrm{Hg}$ for $1 \mathrm{~min}$ before deflation and withdrawal. The distention was repeated twice with a 30 -min break. CRD for adult rats was established 8 weeks later in which an $80 \mathrm{~mm} \mathrm{Hg}$ (1 min) distention was given twice with a $5 \mathrm{~min}$ interval. The extent of visceral hypersensitivity was assessed with abdominal withdrawal reflex (AWR) scores, pain threshold, and electromyography activities of oblique muscles as described previously (Zhang et al., 2015).

\section{Chronic Constriction Injury (CCl) Neuropathic Pain Model}

The chronic neuropathic pain model was generated using a chronic sciatic nerve compression injury method (Bennett and Xie, 1988). Rats were anaesthetized with intraperitoneal injection of $10 \%$ chloral hydrate at $400 \mathrm{mg} / \mathrm{kg}$. After anaesthetization and disinfection, the sciatic nerve trunk was isolated and ligated for a total of four ligations at an interval of $1 \mathrm{~mm}$. The sciatic nerve 
was exposed without ligation treatment in the control group. Paw withdrawal latency (PWL) was used to evaluate the pain level.

\section{Maternal Separation Model}

The protocol of maternal separation was conducted as previously described in detail (Wang et al., 2015). The male and female rats were mated to produce litters. After birth, the pups were randomly divided into two groups: the maternal separation group and the non-maternal separation group. Neonatal mice were separated from mothers for $4 \mathrm{~h}$ (10:00 a.m.-2:00 p.m.) per day ranging from postnatal day 1 to day 15, and maintained on a water-heating pad $\left(29 \pm 1^{\circ} \mathrm{C}\right)$ separately from their littermates. The pups in non-maternal separation group remained in their home cages with their mothers and littermates during the $4 \mathrm{~h}$ separation.

\section{Acetic Acid-Elicited Acute Visceral Pain}

Intraperitoneal acetic acid-induced abdominal contraction was used to establish the acute pain model (Martinez et al., 1999). In brief, mice were placed individually in a standard polycarbonate cage, and allowed to habituate to the environment for $30 \mathrm{~min}$. Acetic acid (0.6\% in distilled water) was injected intraperitoneally in a volume of $10 \mathrm{ml} / \mathrm{kg}$. Immediately after the acetic acid or vehicle injection, pain responses were scored by counting the number of abdominal contractions (writhing test) in $15 \mathrm{~min}$ intervals for $1 \mathrm{~h}$. An abdominal contraction was defined as a lengthwise stretching of the torso with a concomitant arching of the back.

\section{Zymosan-Induced Paw Inflammatory Pain}

Intraplantar injections of zymosan $(1.25 \mathrm{mg} / 100 \mu \mathrm{l})$ were utilized to induce paw inflammation. Sham group received an equal volume of saline. The thermal latencies of the rats were measured pre- and $0.5,1,2,4,8$, and $24 \mathrm{~h}$ post-injection.

\section{Immunofluorescence Labeling}

Rats were deeply anesthetized with $10 \%$ chloral hydrate (250 mg/kg) and perfused transcardially with $300 \mathrm{ml} 0.9 \%$ saline, followed by $4 \%$ paraformaldehyde. The entire brain was quickly removed and further fixed in $4 \%$ paraformaldehyde for $48 \mathrm{~h}$ at $4^{\circ} \mathrm{C}$ before being equilibrated in a $30 \%$ sucrose solution at $4^{\circ} \mathrm{C}$ for 2 days. Double immunofluorescence labeling was used to identify $\triangle$ FosB protein distribution in particular cell types. The $\mathrm{mPFC}$ region was cut in $30-\mu \mathrm{m}$ thick slices with a cryostat (Leica CM1800; Heidelberg, Germany). Selected sections were washed with PBS for 5 min three times, and then incubated with $10 \%$ donkey serum in PBS containing $0.3 \%$ Triton-X-100 for $2 \mathrm{~h}$ at room temperature before incubation with rabbit anti-delta Fosb antibody (1:500, \#9890, Cell Signaling Technology), antineuronal nuclei (NeuN) antibody (1:200; MAB377X, Millipore), anti-glial fibrillary acidic protein (GFAP; 1:200; \#3670, Cell Signaling Technology), or anti-ionized calcium-binding adaptor molecule 1 (Iba-1; 1:200; ab5076, Abcam) at $4^{\circ} \mathrm{C}$ for $24 \mathrm{~h}$. Alexa 488 donkey anti-rabbit IgG (1:200), Alexa 594 donkey antimouse IgG (1:200), or Alexa 594 donkey anti-goat IgG (1:200) were added to the corresponding sections and incubated for $2 \mathrm{~h}$ at room temperature. Tissue sections were mounted with 50\% glycerol mounting medium. Layer $\mathrm{V}$ of the prelimbic cortex on the left hemisphere in each mouse was visualized with a confocal laser microscope (FV1000; Olympus, Tokyo, Japan). Tissue images were processed using Image Pro-Plus 5.0 software (Media Cybernetics, Silver Spring, MD).

\section{Western Blotting Analysis}

The bilateral mPFC and visual cortex were collected from fresh brain and lysed in RIPA lysis buffer containing $50 \mathrm{mM}$ Tris ( $\mathrm{pH} 7.4$ ), $150 \mathrm{mM} \mathrm{NaCl}, 1 \%$ Triton X-100, 1\% sodium deoxycholate, $0.1 \%$ SDS, $1 \mathrm{mM}$ sodium orthovanadate, and $1 \mathrm{mM}$ Phenylmethanesulfonyl fluoride (PMSF). Homogenates were keep on ice for another $30 \mathrm{~min}$ before being centrifuged at $8,000 \mathrm{~g}$ for $5 \mathrm{~min}$ at $4^{\circ} \mathrm{C}$; the supernatant containing the cytoplasmic components was saved at $-80^{\circ} \mathrm{C}$ before analysis. Equal amounts of protein $(80 \mu \mathrm{g})$ were separated by SDS-PAGE, transferred electrophoretically to nitrocellulose membrane, and incubated with rabbit polyclonal anti- $\Delta$ FosB overnight at $4^{\circ} \mathrm{C}$. The membrane was washed thoroughly and incubated with AP-conjugated secondary antibody (1:1000) for $2 \mathrm{~h}$ at room temperature. Protein bands were visualized using the BCIP/NBT Alkaline Phosphatase Color Development Kit and quantified using Image $J$ software (National Institutes of Health).

\section{Statistical Analysis}

Data were expressed as mean \pm SEM. The time-course of the number of abdominal contraction was analyzed by a two-way repeated measures ANOVA. Student's $t$-test, one-way ANOVA, and two-way ANOVA were also used. If significance was found, post hoc Bonferroni multiple comparison was used. All statistical tests were conducted using SPSS 19.0 software package (IBM, Armonk, NY, USA) with $p<0.05$ considered statistically significant.

\section{RESULTS}

\section{Neonatal CRD Exposure is Associated with an Increase in Adult $\Delta$ FosB Protein Expression in MPFC}

The $\Delta$ FosB protein labeling was compared with neuronal marker NeuN, microglial marker Iba-1 and astrocyte marker GFAP. The top row in Figure $1 \mathrm{~A}$ shows the $\triangle$ FosB and NeuN staining in prelimbic area of drug-naïve rats. Rows 2-4 in Figure 1A illustrate protein staining in rats that had experienced neonatal and adult CRDs. As compared to drugnaïve rats, the rats experienced $C R D$ s presented a significant increase in NeuN and $\triangle$ FosB immunoreactivity. $\triangle$ FosB was visualized in pyramidal neurons marked by NeuN staining (Figure 1A). A two-way ANOVA on body weight revealed a significant main effect of neonatal CRDs $[F(1,8)=218.56$, $p<0.01]$, a significant main effect of adult $C R D[F(1,8)=8.80$, $p<0.05]$, but not the neonatal $\times$ adult $C R D$ s interaction $[F(1,8)=6.39, p=0.035](n=8$ in each group; Figure 1B). As compared to naïve rats, there was a significant increase in 


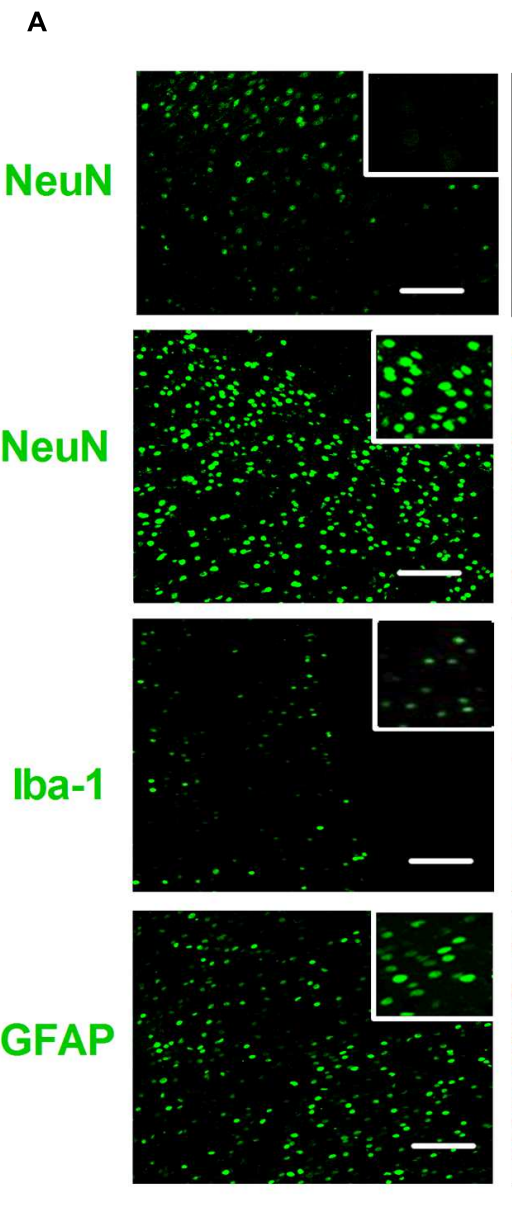

B

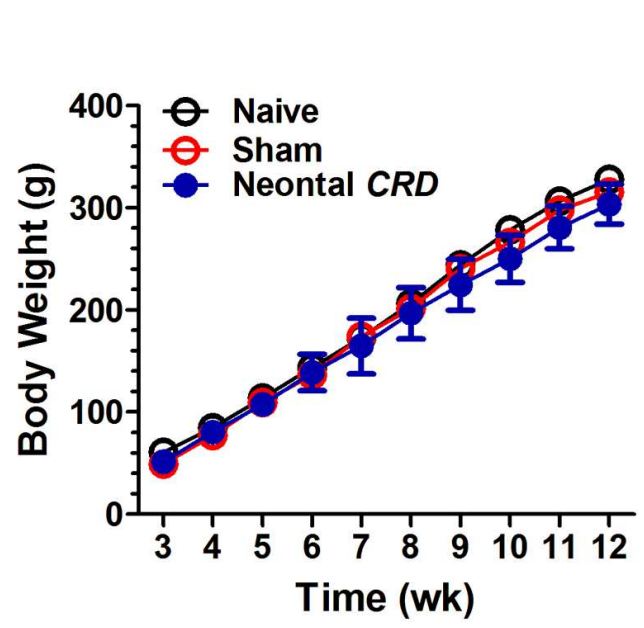

$\Delta$ FosB
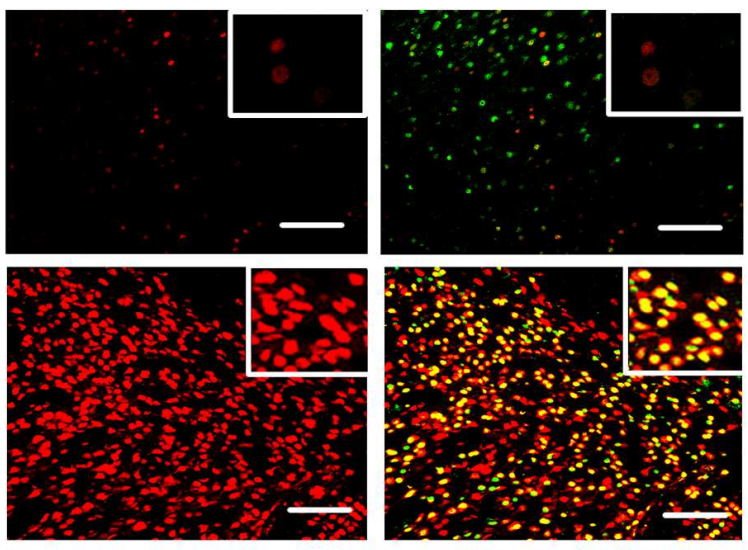

NeuN/AFosB

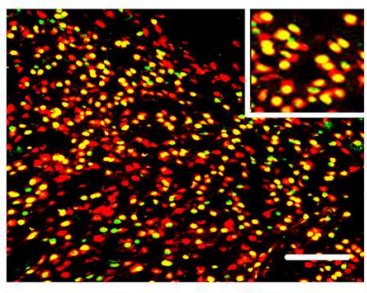

\section{NeuN/AFosB}
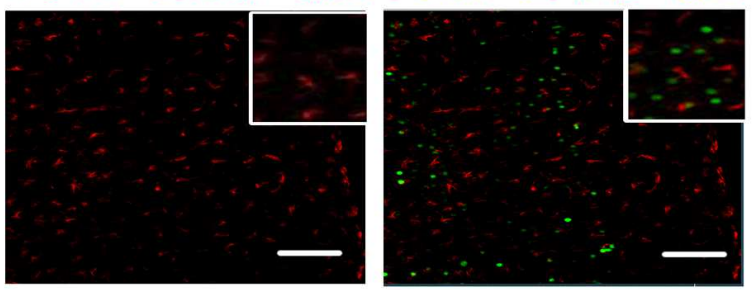

Iba-1/AFosB
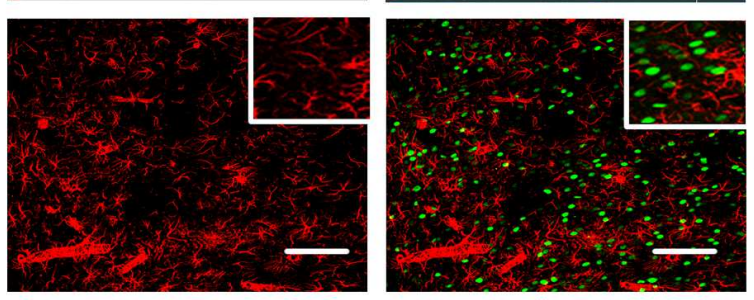

GFAPIAFosB
C

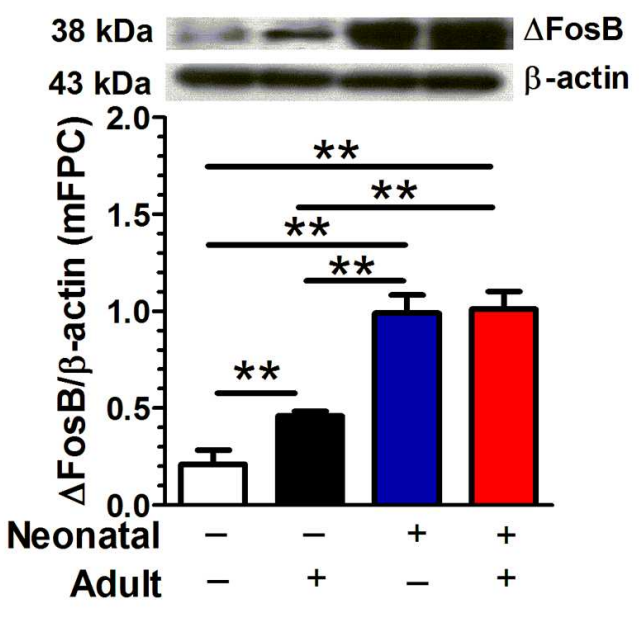

FIGURE 1 | Neonatal colorectal distension (CRD) exposure is associated with an increase in adult $\triangle$ FosB expression in mFPC. $\triangle$ FosB protein labeling was compared with neuronal marker NeuN, microglial marker lba-1 and astrocyte marker GFAP. $\triangle$ FosB was visualized in pyramidal neurons marked by NeuN staining. Row one came from drug-naiive rats, and rows 2 to 4 was from rats that experienced neonatal and adult CRDs. Scale bar $=100 \mu \mathrm{m}$ (A). Mice received neonatal and/or adult colorectal distension. There was no difference in body weight. (B; $n=8$ per group). A two-way ANOVA on $\triangle$ FosB expression revealed a significant main effect of neonatal CRDs $(p<0.01)$ and a significant main effect of adult CRDs $(p<0.05)$. Rats that experienced neonatal or a combination of neonatal and adult $C R D$ s presented a significant increase in $\triangle F$ osB expression compared with rats without $C R D$ s or adult $C R D$ only (C). Data were expressed as mean $\pm \mathrm{SEM}, n=3$ in each group. ${ }^{* *} p<0.01$. 
$\triangle$ FosB protein expression in rats that had experienced neonatal $C R D s[t(4)=11.46, p<0.01]$, adult CRDs $[t(4)=4.98$, $p<0.01]$ or a combination of neonatal and adult CRDs $[t(4)=11.78, p<0.01]$. Adult $C R D$ rats presented a significantly lower expression of $\triangle$ FosB protein levels as compared with rats that had experienced neonatal CRDs $[t(4)=8.99$, $p<0.01]$ or a combination of neonatal and adult CRDs $[t(4)=0.9 .35, p<0.01]$. There was no difference between rats that had experienced neonatal CRDs and those with a combination of neonatal + adult CRDs $[t(4)=0.26, p=0.81]$ (Figure 1C).

\section{Chronic Constriction Injury Is Associated with an Increase in Adult $\Delta$ FosB Protein Expression in mPFC}

The CCI in rats altered the PWL score (Figure 2A). A oneway ANOVA showed a significant difference $[F(2,48)=61.51$, $p<0.01$ ]; Post hoc Bonferroni's multiple comparisons showed that CCI rats $(n=17)$ presented a significant decrease in PWL as compared to control $(n=17 ; p<0.01)$ or sham rats $(n=17$; $p<0.01)$. There was no difference between control and sham rats. The CCI in rats altered the $\triangle$ FosB protein expression (Figure 2B). A one-way ANOVA showed a significant difference $[F(2,9)=174.7, p<0.01]$; Post hoc Bonferroni's multiple comparisons CCI rats $(n=4)$ presented a significant increase in $\Delta$ FosB expression as compared to control $(n=4 ; p<0.01)$ and sham rats $(n=4 ; p<0.01)$. Sham rats presented a significant increase in $\Delta$ FosB protein expression as compared to control rats $(p<0.01)$. On the other hand, $\Delta$ FosB protein expression in the visual cortex was not statistically different between control, sham and CCI rats $[F(2,6)=0.02, p=0.98 ; n=3$ per group; Figure 2C].

\section{Maternal Separation Is Associated with an Increase in Adult $\Delta$ FosB Expression in $\mathrm{MPFC}$}

Rats that underwent maternal separation presented a significant increase in $\triangle$ FosB protein expression in $\mathrm{mPFC}$ compared with that in the control group $[t(4)=4.95, p<0.01, n=3$ per group; Figure 3].

\section{Acetic Acid-Induced Acute Visceral Pain Does Not Affect $\Delta$ FosB Expression in mPFC}

Intraperitoneal injection of $0.6 \%$ acetic acid increased the number of abdominal contractions compared with that in the control group (Figure 4A). A two-way repeated measures ANOVA revealed a significant main effect of treatment $[F(1,18)=599.51$, $p<0.01]$, a significant main effect of time $[F(3,54)=123.39$, $p<0.01]$, and a significant time $\times$ treatment interaction $[F(3,54)=123.39, p<0.01, n=10$ per group]. There was no significant difference in $\triangle$ FosB expression in $\mathrm{mPFC}$ between acetic acid group and control group $[F(4,19)=0.32, p=0.86$, $n=3$; Figure $4 \mathrm{~B}]$. The $\Delta$ FosB expression in the visual cortex was not found to be statistically different between vehicle and acetic acid-treated rats $[t(4)=0.14, p=0.89 ; n=3$; Figure $4 \mathrm{C}]$.

\section{Zymosan-Induced Paw Inflammatory Pain Does Not Affect $\Delta$ FosB Expression in $\mathrm{MPFC}$}

Intrapaw injection of zymosan decreased the latency of paw withdrawal compared with that in control group (Figure 5A). A two-way repeated measures ANOVA revealed a significant main effect of treatment $[F(1,10)=157.97, p<0.01]$, a significant
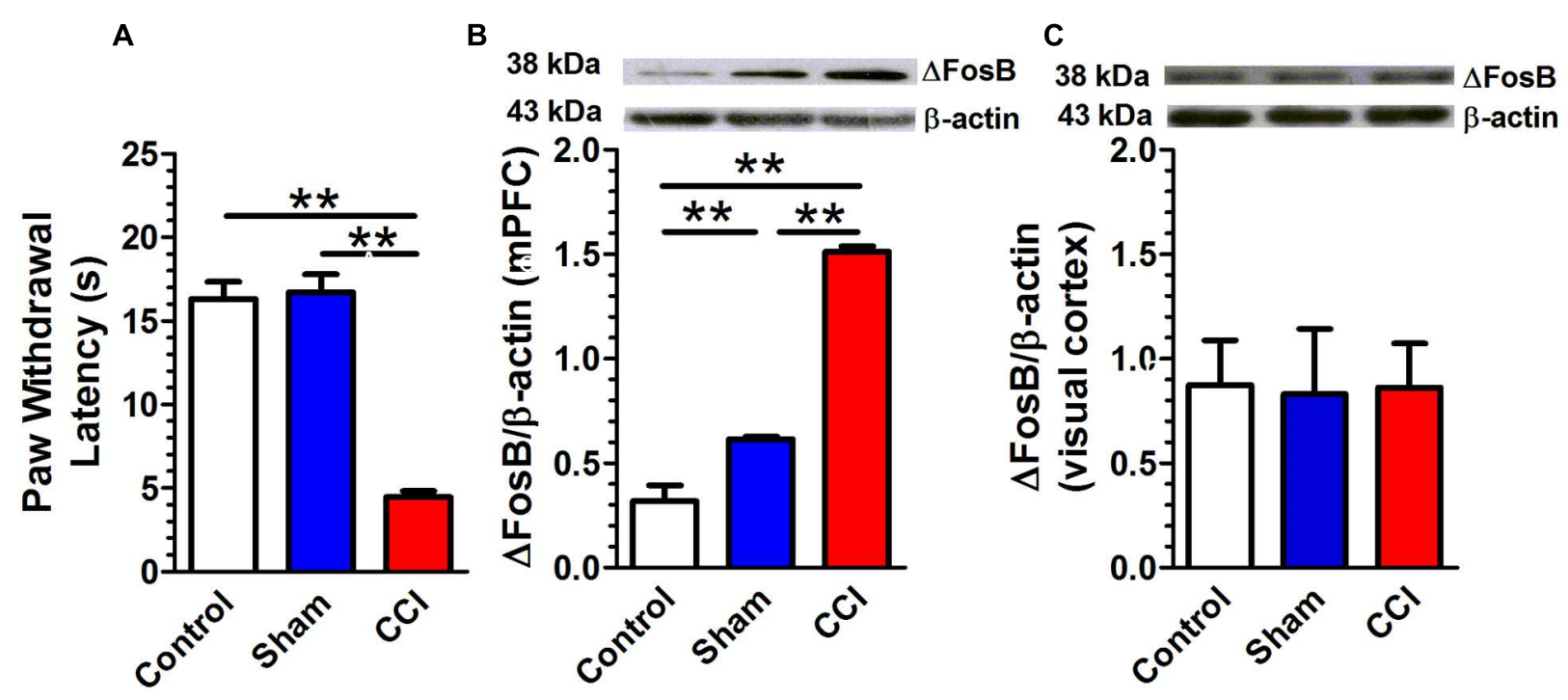

FIGURE 2 | Chronic constriction injury $(\mathbf{C C l})$ is associated with an increase in adult $\Delta$ FosB expression in $\mathbf{m P F C}$. Rats that received CCl of the sciatic nerve presented a significant decrease in paw withdrawal latency (PWL; $\mathbf{A} ; n=17$ per group) and a significant increase in $\Delta$ FosB expression. (B; $n=4$ per group) compared with control or sham rats. There was no change in $\Delta$ FosB expression in the visual cortex between control, sham and CCl groups. $(\mathbf{C} ; n=3$ per group). Data were expressed as mean $\pm \mathrm{SEM}, * * p<0.01$. 


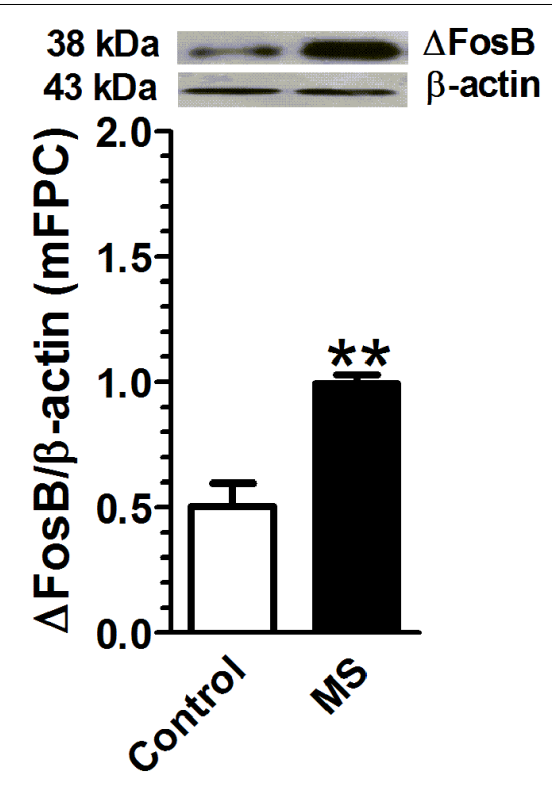

FIGURE 3 | Maternal separation is associated with an increase in adult $\triangle F$ osB expression in mPFC. Rats exposed to maternal separation exhibited a significant increase in $\triangle$ FosB expression in mPFC compared with that in the control group ( $p<0.01, n=3$ ). Data were expressed as mean \pm SEM, ${ }^{* *} p<0.01$ vs. control.

main effect of time $[F(6,60)=37.60, p<0.01]$, and significant time $\times$ treatment interaction $[F(6,60)=27.84, p<0.01$, $n=6$ per group]. There was no significant difference in $\Delta$ FosB expression in $\mathrm{mPFC}$ between zymosan-group and control group $[F(6,14)=0.97, p=0.48, n=3$; Figure 5B $]$.

\section{DISCUSSION}

In this study, we examined $\triangle F$ FosB protein expression in animals that experienced acute or chronic stress-induced pain. Our data reveal an increase in $\triangle F o s B$ expression in animals with chronic pain induced by CRD, CCI, and maternal separation, but not in acetic acid-induced acute visceral pain and zymosan-induced acute inflammatory pain. $\Delta$ FosB protein expression in the visual cortex did not change as a result of CCI or acetic acid-induced pain. These results suggest that $\triangle$ FosB may be an important transcriptional factor that modulates neuronal adaptation specifically to chronic stress-induced pain. Elucidation of the molecular mechanisms that are responsible for the specific $\Delta$ FosB response to chronic pain provides new opportunities for therapeutic approaches to prevent acute pain translated into chronic pain.

Our data indicate that $\Delta \mathrm{FosB}$ protein expression is increased in rats that experienced neonatal CRDs. Visceral hypersensitivity is a major contributor to irritable bowel syndrome and other disorders with chronic visceral pain (Chey et al., 2015). The pathogenesis of visceral hypersensitivity remains speculative due to undetectable structural abnormalities in the peripheral organs
(Chen et al., 2015). In the present study, visceral hypersensitivity was developed by neonatal and adult CRDs in rats. We did not find any identifiable behavioral abnormalities in adult rats that experienced neonatal CRDs (Chen et al., 2015; Zhang et al., 2015), but adult re-exposure to CRD precipitated behavioral abnormalities and visceral pain hypersensitivity only in rats that experienced neonatal CRDs (Zhang et al., 2015). These results suggest that neonatal CRDs alter the neuronal traits, in spite of the body maintaining a normal phenotype through adaptation. Such a quiescent event can be prompted by a subthreshold stressor imposed late in life, and induces changes in genotype and phenotype, such as fear reaction, cognition, dysthymia, novelty-seeking, and pain perception (Charmandari et al., 2003). Our data indicate that the neonatal CRD is associated with a significant increase in $\triangle F$ osB protein expression in mPFC.

Chronic neuropathic pain is a prevalent and debilitating condition, affecting $7-18 \%$ of the population (Bouhassira et al., 2008; Toth et al., 2009). Clinical manifestation includes spontaneous pain, dysaesthesia, paraesthesia, allodynia, and hyperalgesia. The sensory symptoms are co-morbid with mental impairments, such as insomnia and depression. CCI of the sciatic nerve is a chronic neuropathic pain resulting from damage to the peripheral nervous system. The CCI model is a popular tool to study mechanisms for chronic neuropathic pain and to identify experimental compounds with analgesic properties that are palliative for chronic neuropathic pain. Unilateral CCI to the infraorbital nerve induces a strong, bilateral upregulation of pERK-1/2 in the ventral mPFC of rats (Devoize et al., 2011). Our data reveal an increase in the expression of $\triangle F$ osB in $\mathrm{mPFC}$ in rats that experienced CCI. Interestingly, CCI did not alter $\Delta$ FosB expression in the visual cortex, a non pain-related brain region.

Early life adversity, such as postnatal maternal separation, plays a central role in the development of psychopathologies during individual ontogeny. The adverse early life event is a risk factor for the development of psychiatric diseases in adult. In rats, maternal separation, which deprives pups of their mothers, has often been used as a model for early life adversity (Hall, 1998). Maternal separation has been demonstrated to induce behavioral and cognitive abnormalities, such as increased depressive and anxiety-like behaviors (Rentesi et al., 2010) and prepulse inhibition and learning deficits (Garner et al., 2007). Maternal separation has also been shown to decrease new born cells in the hippocampus and the granular cell in the dentate gyrus of juvenile and adult rats (Hulshof et al., 2011), and decrease the expression of brainderived neurotrophic factor (BDNF) in the $\mathrm{mPFC}$ in young adult rats (Wang et al., 2015). These findings suggest that maternal separation can affect the neuroplasticity of rats. In line with these results, our data revealed an increase in the expression of $\triangle \mathrm{FosB}$ in $\mathrm{mPFC}$ in rats that experienced maternal separation.

Local or intraperitoneal injection of zymosan, a polysaccharide component of the cell wall from Saccharomyces cerevisiae, or acetic acid, represents a self-resolving model of acute inflammation and pain, which has been widely used for the 


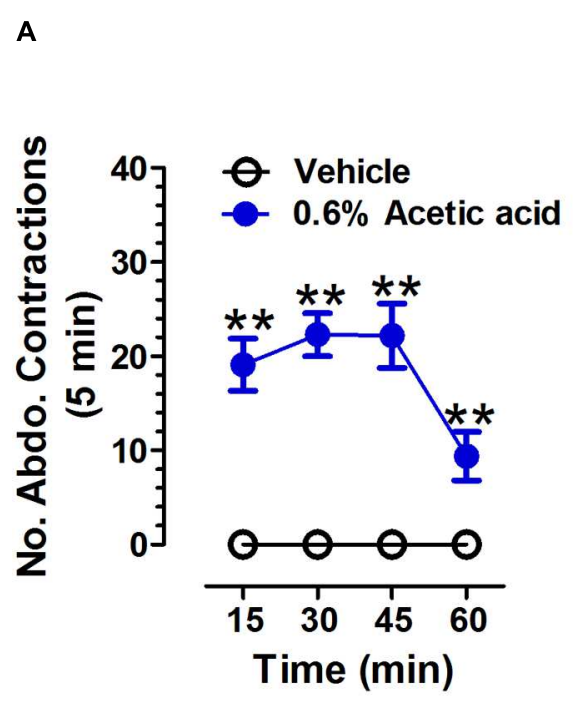

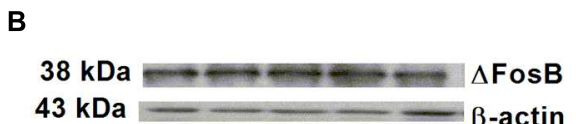

$43 \mathrm{kDa}=\beta$-actin

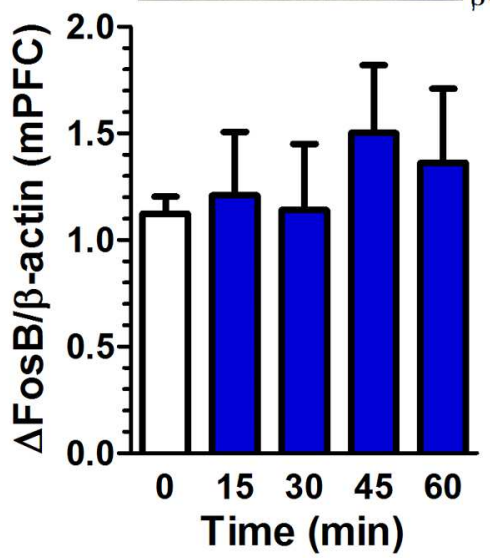

C
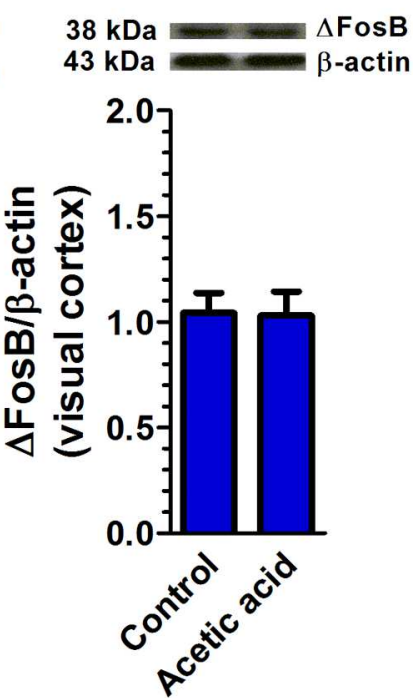

FIGURE 4 | Acetic acid-induced acute pain does not affect $\Delta$ FosB expression in mPFC. Intraperitoneal injection of $0.6 \%$ acetic acid increased the number of abdominal contractions compared with that in control group. (A; $n=10$ per group). The $\Delta$ FosB expression in mPFC was not significantly altered $15,30,45$, and 60 min after acetic acid application. (B; $n=3$ per group). There was no change in $\Delta$ FosB expression in the visual cortex between control and acetic acid-treated groups. (C; $n=3$ per group; brain tissues were collected at 45 min after acetic acid treatment). Data were expressed as mean $\pm \mathrm{SEM},{ }^{* *} p<0.01$ vs. vehicle.

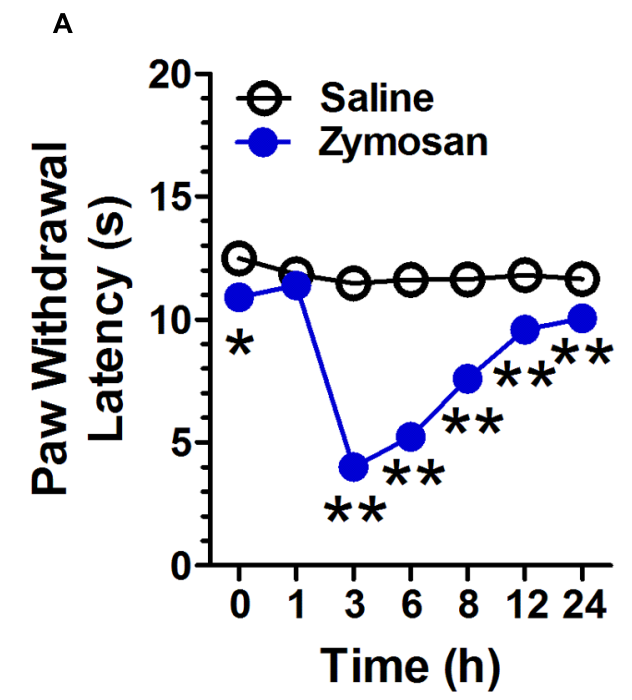

B

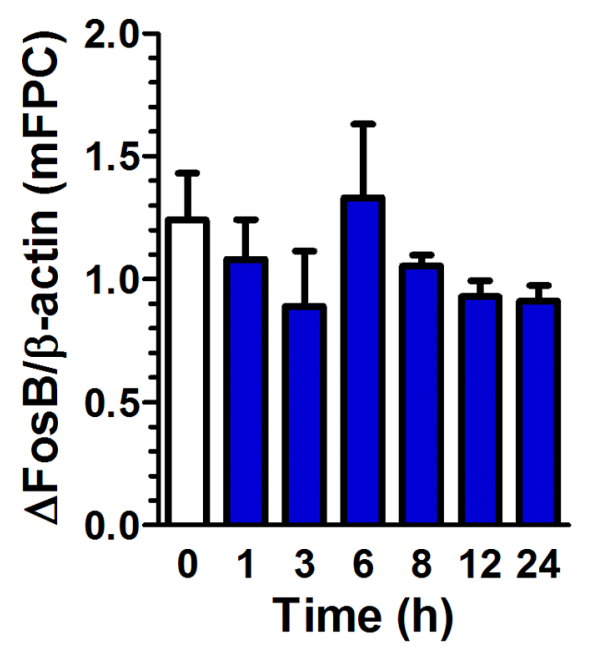

FIGURE 5 | Zymosan-induced paw inflammatory pain does not affect $\triangle$ FosB expression in mPFC. Intrapaw injection of zymosan decreased the latency of paw withdrawal compared to that in the control group. (A; $n=6$ per group). The $\Delta$ FosB expression in mPFC was not significantly altered $1,3,6,8,12$, and $24 \mathrm{~h}$ after zymosan application. (B; $n=3$ per group). Data were expressed as mean $\pm \mathrm{SEM},{ }^{* *} p<0.01$ vs. saline.

quantification of particular cell types and inflammation-related soluble factors (Cash et al., 2009). Intraplantar administration of zymosan in the rat hindpaw produces a reliable and quantifiable thermal and mechanical hyperalgesia accompanied by oedema that closely mimics the symptoms of inflammation in humans (Meller and Gebhart, 1997). Our data indicate that the expression of $\triangle \mathrm{FosB}$ in $\mathrm{mPFC}$ is not altered in rats with acetic acid- or zymosan- induced acute pain. Since $\Delta$ FosB expression is altered only in chronic or persistent exposure to chronic stimuli, it is not surprising that we did not observe the $\Delta \mathrm{FosB}$ change in either the acetic acid- or the zymosan-induced acute pain models.

Early life stress, such as neonatal CRD and maternal separation, is a potential contributor to visceral hypersensitivity and pain (Al-Chaer et al., 2000; Zhou et al., 2010). The developing brain undergoes rapid growth and is characterized 
by high turnover of neuronal wiring. Early life stress affects the developmental trajectory of the neurocircuitry in the CNS and alters vulnerability to subsequent stress during adulthood (Wouters et al., 2012). Early life stress may produce stable changes in neuronal plasticity, function, and communication, and increase susceptibility to developing the enhanced painlike behavioral profiles and later-life psychopathology (Van den Bergh et al., 2008; Green et al., 2011; Amath et al., 2012). The $\triangle \mathrm{FosB}$ protein is elevated in chronic, but not acute stress-induced pain models. It is posited that $\Delta$ FosB functions as a molecular switch that mediates persistent adaptations in the brain response to chronic pain (Luis-Delgado et al., 2006).

The $\Delta$ FosB protein is a unique transcription factor that plays an essential role in long-term adaptive changes in the brain associated with diverse conditions, such as drug addiction, Parkinson's disease, depression, and antidepressant treatment. In CNS, $\triangle \mathrm{FosB}$ expression is regulated in a regional- and celltype-specific manner by many types of chronic perturbations (Nestler et al., 2001; Werme et al., 2002). Once induced, it persists for a long period of time due to its unusual stability. The transcriptional effects of $\Delta \mathrm{FosB}$ are complex, because the protein can function as both a transcriptional activator and repressor. Progress has been made in identifying specific target genes for $\triangle \mathrm{FosB}$ and in relating some of these genes to the cellular and behavioral actions of the $\Delta$ fos $B$ protein. Future studies will help us to better understand the biochemical basis of the $\Delta$ fosB protein's unique stability, as well as the precise molecular pathways through which this transcription factor produces its complex effects on neuronal plasticity and complex behavior (McClung et al., 2004).

The upstream and downstream signaling pathways of $\Delta$ FosB remain largely unknown. Different stimuli can invoke different molecular mechanisms to induce $\Delta$ fos $B$ protein levels. Inflammation is a major contributor to pain. This inflammatory neuroplasticity is the consequence of a combination of activity-dependent changes in the neurons and specific signal molecules initiating particular signal-transduction pathways and altering gene expression (Woolf and Costigan, 1999). We recently demonstrated that activation of microglial toll-like receptor 4 (TLR4)/ myeloid differentiation factor 88 (MyD88)/ nuclear factor $\kappa \mathrm{B}$ (NF$\kappa B)$ signaling, as well as proinflammatory cytokines tumor necrosis factor- $\alpha$ (TNF- $\alpha$ ) and interleukin- $1 \beta$ (IL-1 $\beta$ ) facilitated the development of visceral hypersensitivity and pain (Chen et al., 2015; Zhang et al., 2015). The casual relation between inflammatory modulators and the $\Delta$ FosB protein needs further exploration.

The downstream of $\Delta$ FosB remains elusive. $\Delta$ FosB dimerizes predominantly with JunD to form a heterodimerized AP1 complex (Hiroi et al., 1998). Recent in vitro evidence has indicated that $\triangle \mathrm{FosB}$ can also form homodimers (Jorissen et al., 2007). $\Delta$ FosB acts as either a transcriptional repressor or activator (McClung and Nestler, 2003). A plethora of factors participate in hyperalgesia and allodynia following peripheral tissue inflammation, including cyclin-dependent kinase 5 (CDK5; Chen et al., 2000), cholecystokinin (CCK)B receptor, (Covington et al., 2010) NMDA receptor subunit 1 (NR1; Hiroi et al., 1998) and AMPA ionotropic glutamate receptor subunit 2 (GluR2; Kelz et al., 1999; Rygh et al., 2001). Such data from the literature suggest that the above target genes could be candidates of interest for future studies to understand the action of the $\Delta$ FosB protein in the CNS.

The chronic conditions tested here do not allow separation of pain processing in the mPFC due to stress, depression or anxiety. $\triangle \mathrm{FosB}$ is a transcriptional regulator of stress (Nestler, 2015). Stress, e.g., pain, physical abuse, neonatal maternal separation, or exposure to an immune challenge can induce genetic, physiological and behavioral changes (Mayer and Collins, 2002). The $\Delta$ FosB protein accumulates within the same brain regions after repeated stress exposure, whereas other Fos family members show desensitization [i.e., reduced induction compared with initial drug exposures (Perrotti et al., 2004; Lehmann and Herkenham, 2011)]. Such accumulation of $\triangle F$ FosB has been observed due to several forms of active stress, such as chronic restraint stress, chronic unpredictable stress, and chronic social defeat stress, whereas chronic social isolation decreases $\Delta$ FosB levels in nucleus accumbens (Vialou et al., 2010). Stress induces $\triangle$ FosB expression in mPFC, and that overexpression of $\triangle \mathrm{FosB}$ in pre-limbic $\mathrm{mPFC}$ enhances stress susceptibility in mice (Vialou et al., 2014). The mPFC shows lower basal levels of $\triangle \mathrm{FosB}$ immunoreactivity, but almost a threefold induction after chronic restraint stress in rats (Perrotti et al., 2004). We found rats that experienced neonatal CRD and maternal separation showed an elevation in the $\Delta$ fosB protein levels. Maladaptation of the stress system may impair neuronal development, and account for a number of endocrine, metabolic, autoimmune, and psychiatric disorders (Green et al., 2011; Amath et al., 2012). Antidepressants can reverse this social withdrawal syndrome by boosting $\triangle$ FosB. Moreover, $\triangle \mathrm{FosB}$ is conspicuously depleted in brains of people who suffered from depression. Thus, induction of $\triangle \mathrm{FosB}$ is a positive adaptation for coping with stress. Under most circumstances, stress, depression, anxiety and pain share common contributors and neurobiological inhibitors. In this study, we reported that chronic pain rat models presented an elevation of $\triangle \mathrm{FosB}$ protein level in mFPC. Interestingly, the $\Delta \mathrm{FosB}$ expression in the visual cortex, a non pain-related region of the brain did not change due to CCI or acetic acid treatments, suggesting that $\triangle \mathrm{FosB}$ expression to stress and pain presents a regional specificity. The casual relationship between chronic pain and the $\Delta$ FosB protein need further exploration.

A number of immunostaining studies show that $\Delta \mathrm{FosB}$ expresses predominately in projection neurons (Perrotti et al., 2004; Lobo et al., 2013; Nomaru et al., 2014). In the prefrontal cortex, $\Delta$ FosB exists in several layers of the cortex, in particular in layers II/III and V. The $\Delta$ FosB staining was again localized in the neurons, with no colocalization with GFAP, an astroglial marker seen primarily within cortical pyramidal neurons; over $90 \%$ of the $\Delta$ FosB + cells colabeled with vesicular glutamate transporter 1 (vGluT1; a marker of glutamatergic neurons), with little colabeling seen 
with markers for various GABAergic interneurons (i.e., calbindin, parvalbumin, or calretinin; Perrotti et al., 2004). Based on these data, we predict that chronic stress elevates the $\Delta$ FosB protein expression in pyramidal neurons in $\mathrm{mPFC}$.

\section{CONCLUSION}

Our results clearly show the expression of $\Delta$ FosB was significantly elevated in rats undergoing chronic, but not acute, stress-induced pain. The $\Delta$ FosB protein expression profile to different stimuli supports the role of $\Delta \mathrm{FosB}$ in neuronal plasticity and suggests that it could be a useful molecular marker of sustained pain. Further research is needed to improve our understanding of both the upstream mechanism leading to $\Delta$ FosB protein production and the downstream mechanism by which the $\Delta$ FosB protein might participate in plasticity.

\section{REFERENCES}

Al-Chaer, E. D., Kawasaki, M., and Pasricha, P. J. (2000). A new model of chronic visceral hypersensitivity in adult rats induced by colon irritation during postnatal development. Gastroenterology 119, 1276-1285. doi: 10.1053/gast.2000.19576

Amath, A., Foster, J. A., and Sidor, M. M. (2012). Developmental alterations in CNS stress-related gene expression following postnatal immune activation. Neuroscience 220, 90-99. doi: 10.1016/j.neuroscience.2012.06.037

Andersson, M., Westin, J. E., and Cenci, M. A. (2003). Time course of striatal DeltaFosB-like immunoreactivity and prodynorphin mRNA levels after discontinuation of chronic dopaminomimetic treatment. Eur. J. Neurosci. 17, 661-666. doi: 10.1046/j.1460-9568.2003.02469.x

Baliki, M. N., Mansour, A. R., Baria, A. T., and Apkarian, A. V. (2014). Functional reorganization of the default mode network across chronic pain conditions. PLoS ONE 9:e106133. doi: 10.1371/journal.pone.0106133

Bennett, G. J., and Xie, Y. K. (1988). A peripheral mononeuropathy in rat that produces disorders of pain sensation like those seen in man. Pain 33, 87-107. doi: 10.1016/0304-3959(88)90209-6

Bouhassira, D., Lanteri-Minet, M., Attal, N., Laurent, B., and Touboul, C. (2008). Prevalence of chronic pain with neuropathic characteristics in the general population. Pain 136, 380-387. doi: 10.1016/j.pain.2007.08.013

Cash, J. L., White, G. E., and Greaves, D. R. (2009). Chapter 17. Zymosaninduced peritonitis as a simple experimental system for the study of inflammation. Methods Enzymol. 461, 379-396. doi: 10.1016/S0076-6879(09) 05417-2

Charmandari, E., Kino, T., Souvatzoglou, E., and Chrousos, G. P. (2003). Pediatric stress: hormonal mediators and human development. Horm. Res. 59, 161-179. doi: 10.1159/000069325

Chen, J., Zhang, Y., Kelz, M. B., Steffen, C., Ang, E. S., Zeng, L., et al. (2000). Induction of cyclin-dependent kinase 5 in the hippocampus by chronic electroconvulsive seizures: role of [Delta]FosB. J. Neurosci. 20, 8965-8971.

Chen, Z. Y., Zhang, X. W., Yu, L., Hua, R., Zhao, X. P., Qin, X., et al. (2015). Spinal toll-like receptor 4-mediated signalling pathway contributes to visceral hypersensitivity induced by neonatal colonic irritation in rats. Eur. J. Pain 19, 176-186. doi: 10.1002/ejp.534

Chey, W. D., Kurlander, J., and Eswaran, S. (2015). Irritable bowel syndrome: a clinical review. JAMA 313, 949-958. doi: 10.1001/jama.2015.0954

Covington, H. E. III, Lobo, M. K., Maze, I., Vialou, V., Hyman, J. M., Zaman, S., et al. (2010). Antidepressant effect of optogenetic stimulation of the medial prefrontal cortex. J. Neurosci. 30, 16082-16090. doi: 10.1523/JNEUROSCI.1731-10.2010

Devoize, L., Alvarez, P., Monconduit, L., and Dallel, R. (2011). Representation of dynamic mechanical allodynia in the ventral medial prefrontal cortex of trigeminal neuropathic rats. Eur. J. Pain 15, 676-682. doi: 10.1016/j.ejpain.2010.11.017

\section{AUTHOR CONTRIBUTIONS}

Y-MZ and GZ conceived the idea, supervised the research, analyzed the data, and wrote the manuscript. HW conducted the research and wrote the manuscript. All other authors conceived the idea, analyzed the data, and wrote the manuscript. We thank Dr. Diane Baronas-Lowell for proofreading this manuscript.

\section{FUNDING}

This project was supported by grants from the National Natural Science Foundation of China (81171041 to Y-MZ, 81271217 to GZ, 31200836 to YS and 81471161 to XT), Key Subject of Colleges and Universities Natural Science Foundation of Jiangsu Province (13KJA320001 to Y-MZ), and sponsored by the Qing Lan Project.

Garner, B., Wood, S. J., Pantelis, C., and Van Den Buuse, M. (2007). Early maternal deprivation reduces prepulse inhibition and impairs spatial learning ability in adulthood: no further effect of post-pubertal chronic corticosterone treatment. Behav. Brain Res. 176, 323-332. doi: 10.1016/j.bbr.2006.10.020

Green, M. K., Rani, C. S., Joshi, A., Soto-Pina, A. E., Martinez, P. A., Frazer, A., et al. (2011). Prenatal stress induces long term stress vulnerability, compromising stress response systems in the brain and impairing extinction of conditioned fear after adult stress. Neuroscience 192, 438-451. doi: 10.1016/j.neuroscience.2011.06.041

Guida, F., Luongo, L., Marmo, F., Romano, R., Iannotta, M., Napolitano, F., et al. (2015). Palmitoylethanolamide reduces pain-related behaviors and restores glutamatergic synapses homeostasis in the medial prefrontal cortex of neuropathic mice. Mol. Brain 8:47. doi: 10.1186/s13041-015-0139-5

Hall, F. S. (1998). Social deprivation of neonatal, adolescent, and adult rats has distinct neurochemical and behavioral consequences. Crit. Rev. Neurobiol. 12, 129-162. doi: 10.1615/CritRevNeurobiol.v12.i1-2.50

Herdegen, T., and Leah, J. D. (1998). Inducible and constitutive transcription factors in the mammalian nervous system: control of gene expression by Jun, Fos and Krox, and CREB/ATF proteins. Brain Res. Brain Res. Rev. 28, 370-490. doi: 10.1016/S0165-0173(98)00018-6

Hiroi, N., Marek, G. J., Brown, J. R., Ye, H., Saudou, F., Vaidya, V. A., et al. (1998). Essential role of the fosB gene in molecular, cellular, and behavioral actions of chronic electroconvulsive seizures. J. Neurosci. 18, 6952-6962.

Hulshof, H. J., Novati, A., Sgoifo, A., Luiten, P. G., Den Boer, J. A., and Meerlo, P. (2011). Maternal separation decreases adult hippocampal cell proliferation and impairs cognitive performance but has little effect on stress sensitivity and anxiety in adult Wistar rats. Behav. Brain Res. 216, 552-560. doi: 10.1016/j.bbr.2010.08.038

Ji, R. R., Xu, Z. Z., and Gao, Y. J. (2014). Emerging targets in neuroinflammationdriven chronic pain. Nat. Rev. Drug Discov. 13, 533-548. doi: 10.1038/nrd4334

Jorissen, H. J., Ulery, P. G., Henry, L., Gourneni, S., Nestler, E. J., and Rudenko, G. (2007). Dimerization and DNA-binding properties of the transcription factor DeltaFosB. Biochemistry 46, 8360-8372. doi: 10.1021/bi700494v

Kelz, M. B., Chen, J., Carlezon, W. A. Jr., Whisler, K., Gilden, L., Beckmann, A. M., et al. (1999). Expression of the transcription factor deltaFosB in the brain controls sensitivity to cocaine. Nature 401, 272-276. doi: 10.1038/45790

Lehmann, M. L., and Herkenham, M. (2011). Environmental enrichment confers stress resiliency to social defeat through an infralimbic cortexdependent neuroanatomical pathway. J. Neurosci. 31, 6159-6173. doi: 10.1523/JNEUROSCI.0577-11.2011

Lobo, M. K., Zaman, S., Damez-Werno, D. M., Koo, J. W., Bagot, R. C., Dinieri, J. A., et al. (2013). DeltaFosB induction in striatal medium spiny neuron subtypes in response to chronic pharmacological, emotional, and optogenetic stimuli. J. Neurosci. 33, 18381-18395. doi: 10.1523/JNEUROSCI.1875-13.2013

Luis-Delgado, O. E., Barrot, M., Rodeau, J. L., Ulery, P. G., Freund-Mercier, M. J., and Lasbennes, F. (2006). The transcription factor DeltaFosB is recruited 
by inflammatory pain. J. Neurochem. 98, 1423-1431. doi: 10.1111/j.14714159.2006.03970.x

Martinez, V., Thakur, S., Mogil, J. S., Tache, Y., and Mayer, E. A. (1999). Differential effects of chemical and mechanical colonic irritation on behavioral pain response to intraperitoneal acetic acid in mice. Pain 81, 179-186. doi: 10.1016/S0304-3959(99)00008-1

Mayer, E. A., and Collins, S. M. (2002). Evolving pathophysiologic models of functional gastrointestinal disorders. Gastroenterology 122, 2032-2048. doi: 10.1053/gast.2002.33584

McClung, C. A., and Nestler, E. J. (2003). Regulation of gene expression and cocaine reward by CREB and DeltaFosB. Nat. Neurosci. 6, 1208-1215. doi: $10.1038 / \mathrm{nn} 1143$

McClung, C. A., Ulery, P. G., Perrotti, L. I., Zachariou, V., Berton, O., and Nestler, E. J. (2004). DeltaFosB: a molecular switch for long-term adaptation in the brain. Brain Res. Mol. Brain Res. 132, 146-154. doi: 10.1016/j.molbrainres.2004.05.014

Meller, S. T., and Gebhart, G. F. (1997). Intraplantar zymosan as a reliable, quantifiable model of thermal and mechanical hyperalgesia in the rat. Eur. J. Pain 1, 43-52. doi: 10.1016/S1090-3801(97)90052-5

Metz, A. E., Yau, H. J., Centeno, M. V., Apkarian, A. V., and Martina, M. (2009). Morphological and functional reorganization of rat medial prefrontal cortex in neuropathic pain. Proc. Natl. Acad. Sci. U.S.A. 106, 2423-2428. doi: 10.1073/pnas.0809897106

Morgan, J. I., and Curran, T. (1995). Immediate-early genes: ten years on. Trends Neurosci. 18, 66-67. doi: 10.1016/0166-2236(95)80022-T

Morris, T. A., Jafari, N., and Delorenzo, R. J. (2000). Chronic DeltaFosB expression and increased AP-1 transcription factor binding are associated with the long term plasticity changes in epilepsy. Brain Res. Mol. Brain Res. 79, 138-149. doi: 10.1016/S0169-328X(00)00112-1

Nakabeppu, Y., and Nathans, D. (1991). A naturally occurring truncated form of FosB that inhibits Fos/Jun transcriptional activity. Cell 64, 751-759. doi: 10.1016/0092-8674(91)90504-R

Nestler, E. J. (2015). FosB: a transcriptional regulator of stress and antidepressant responses. Euro. J. Pharmacol. 753, 66-72. doi: 10.1016/j.ejphar.2014.10.034

Nestler, E. J., Barrot, M., and Self, D. W. (2001). DeltaFosB: a sustained molecular switch for addiction. Proc. Natl. Acad. Sci. U.S.A. 98, 11042-11046. doi: 10.1073/pnas.191352698

Nestler, E. J., Kelz, M. B., and Chen, J. (1999). DeltaFosB: a molecular mediator of long-term neural and behavioral plasticity. Brain Res. 835, 10-17. doi: 10.1016/S0006-8993(98)01191-3

Nomaru, H., Sakumi, K., Katogi, A., Ohnishi, Y. N., Kajitani, K., Tsuchimoto, D., et al. (2014). Fosb gene products contribute to excitotoxic microglial activation by regulating the expression of complement C5a receptors in microglia. Glia 62 , 1284-1298. doi: 10.1002/glia.22680

Perrotti, L. I., Hadeishi, Y., Ulery, P. G., Barrot, M., Monteggia, L., Duman, R. S., et al. (2004). Induction of deltaFosB in reward-related brain structures after chronic stress. J. Neurosci. 24, 10594-10602. doi: 10.1523/JNEUROSCI.254204.2004

Rentesi, G., Antoniou, K., Marselos, M., Fotopoulos, A., Alboycharali, J., and Konstandi, M. (2010). Long-term consequences of early maternal deprivation in serotonergic activity and HPA function in adult rat. Neurosci. Lett. 480, 7-11. doi: 10.1016/j.neulet.2010.04.054

Rygh, L. J., Svendsen, F., Hole, K., and Tjolsen, A. (2001). Increased spinal $\mathrm{N}$-methyl-D-aspartate receptor function after $20 \mathrm{~h}$ of carrageenan-induced inflammation. Pain 93, 15-21. doi: 10.1016/S0304-3959(01)00286-X

Sheng, M., and Greenberg, M. E. (1990). The regulation and function of c-fos and other immediate early genes in the nervous system. Neuron 4, 477-485. doi: 10.1016/0896-6273(90)90106-P
Toth, C., Lander, J., and Wiebe, S. (2009). The prevalence and impact of chronic pain with neuropathic pain symptoms in the general population. Pain Med. 10, 918-929. doi: 10.1111/j.1526-4637.2009.00655.x

Van den Bergh, B. R., Van Calster, B., Smits, T., Van Huffel, S., and Lagae, L. (2008). Antenatal maternal anxiety is related to HPA-axis dysregulation and self-reported depressive symptoms in adolescence: a prospective study on the fetal origins of depressed mood. Neuropsychopharmacology 33, 536-545. doi: 10.1038/sj.npp.1301540

Vialou, V., Bagot, R. C., Cahill, M. E., Ferguson, D., Robison, A. J., Dietz, D. M., et al. (2014). Prefrontal cortical circuit for depression- and anxiety-related behaviors mediated by cholecystokinin: role of DeltaFosB. J. Neurosci. 34, 3878-3887. doi: 10.1523/JNEUROSCI.1787-13.2014

Vialou, V., Robison, A. J., Laplant, Q. C., Covington, H. E. III, Dietz, D. M., Ohnishi, Y. N., et al. (2010). DeltaFosB in brain reward circuits mediates resilience to stress and antidepressant responses. Nat. Neurosci. 13, 745-752. doi: $10.1038 / \mathrm{nn} .2551$

Wang, Q., Shao, F., and Wang, W. (2015). Maternal separation produces alterations of forebrain brain-derived neurotrophic factor expression in differently aged rats. Front. Mol. Neurosci. 8:49. doi: 10.3389/fnmol.2015. 00049

Werme, M., Messer, C., Olson, L., Gilden, L., Thoren, P., Nestler, E. J., et al. (2002). Delta FosB regulates wheel running. J. Neurosci. 22, 8133-8138.

Woolf, C. J., and Costigan, M. (1999). Transcriptional and posttranslational plasticity and the generation of inflammatory pain. Proc. Natl. Acad. Sci. U.S.A. 96, 7723-7730. doi: 10.1073/pnas.96.14.7723

Wouters, M. M., Van Wanrooy, S., Casteels, C., Nemethova, A., De Vries, A., Van Oudenhove, L., et al. (2012). Altered brain activation to colorectal distention in visceral hypersensitive maternal-separated rats. Neurogastroenterol. Motil. 24:e297. doi: 10.1111/j.1365-2982.2012.01919.x

Zachariou, V., Bolanos, C. A., Selley, D. E., Theobald, D., Cassidy, M. P., Kelz, M. B., et al. (2006). An essential role for DeltaFosB in the nucleus accumbens in morphine action. Nat. Neurosci. 9, 205-211. doi: 10.1038/ nn 1636

Zhang, G., Zhao, B. X., Hua, R., Kang, J., Shao, B. M., Carbonaro, T. M., et al. (2015). Hippocampal microglial activation and glucocorticoid receptor down-regulation precipitate visceral hypersensitivity induced by colorectal distension in rats. Neuropharmacology 102, 295-303. doi: 10.1016/j.neuropharm.2015.11.028

Zhang, Y., Crofton, E. J., Li, D., Lobo, M. K., Fan, X., Nestler, E. J., et al. (2014). Overexpression of DeltaFosB in nucleus accumbens mimics the protective addiction phenotype, but not the protective depression phenotype of environmental enrichment. Front. Behav. Neurosci. 8:297. doi: 10.3389/fnbeh.2014.00297

Zhou, Q., Fillingim, R. B., Riley, J. L. III, Malarkey, W. B., and Verne, G. N. (2010). Central and peripheral hypersensitivity in the irritable bowel syndrome. Pain 148, 454-461. doi: 10.1016/j.pain.2009.12.005

Conflict of Interest Statement: The authors declare that the research was conducted in the absence of any commercial or financial relationships that could be construed as a potential conflict of interest.

Copyright (C) 2016 Wang, Tao, Huang, Wu, Tang, Song, Zhang and Zhang. This is an open-access article distributed under the terms of the Creative Commons Attribution License (CC BY). The use, distribution or reproduction in other forums is permitted, provided the original author(s) or licensor are credited and that the original publication in this journal is cited, in accordance with accepted academic practice. No use, distribution or reproduction is permitted which does not comply with these terms. 